\title{
Anthropogenic Enhancement of Earthquakes in the Conterminous USA
}

\author{
Marilia Hagen', Anibal Azevedo² \\ ${ }^{1}$ Universidade Federal Fluminense, Instituto de Física, Niterói, Brazil \\ ${ }^{2}$ Faculdade de Ciências Aplicadas da Unicamp, Limeira, Brazil \\ Email: marhagen@indiana.edu, anibal.azevedo@fca.unicamp.br
}

How to cite this paper: Hagen, M. and Azevedo, A. (2017) Anthropogenic Enhancement of Earthquakes in the Conterminous USA. Journal of Geoscience and Environment Protection, 5, 69-87. https://doi.org/10.4236/gep.2017.56009

Received: May 5, 2017

Accepted: June 11, 2017

Published: June 14, 2017

Copyright $\odot 2017$ by author and Scientific Research Publishing Inc. This work is licensed under the Creative Commons Attribution International License (CC BY 4.0).

http://creativecommons.org/licenses/by/4.0/

\section{cc) (i) Open Access}

\begin{abstract}
Since the 1950s, small tremors created by human actions have been catalogued and recorded by the USGS. However, there is no academic explanation of the mechanism involved in these quakes. The aim of this work is to show that the propagation of mechanical fractures created in certain areas is one factor responsible for triggering earthquakes. Technically, this fracturing process depends on the ratio between pressure and tension, i.e., Young's modulus, and locally depends on the specific material under pressure. Examining the entire territory of the U.S., we were able to identify certain states where Griffith's theory was applied to explain the results found in those states. This study works with public records available from USGS. Therefore, any classified event or information is outside of the scope of this paper. We also investigate mid-continent or intraplate earthquakes during the period 2000-2016 with magnitudes M2 to M3.8 in shallow depths that appear to be amplified in consonance with development by companies in fracking, oil-gas assessment, mining, quarry blasting, experimental explosions, and collapses. Of particular interest was the enhancement of earthquakes during 2000-2016 for events $M$ $\geq 4$ surrounding the Mississippi Lime near the Oklahoma/Kansas border. Overall, all the anthropogenic events could be elucidated by Griffith theory.
\end{abstract}

\section{Keywords}

Anthropogenic, Intraplate Earthquakes, Griffith Theory, Young Modulus

\section{Introduction}

A recent history of relevant intraplate earthquakes in the U.S. includes two significant events in 2011: M5.8, in Mineral, Virginia, and M5.7 in Oklahoma. [1] Much earlier events, in chronological order, include New York City (estimated at M5.5), Boston (Cape Ann) in 1755 with magnitude 6.0 to 6.3, New Madrid in 
1811 and 1812 with magnitude as high as 8.1, New York City in 1884 (estimated at M5.5 again), and the1886 Charleston, South Carolina quake with magnitudes estimated at 6.5 to 7.3 [2] [3] [4]. Several questions remain unanswered as to the causes of intraplate earthquakes. In various cases, the fault is difficult and sometimes nearly impossible to find. This increases the difficulty of calculating a locale's specific seismic hazard, particularly for regions with few recorded earthquakes, [5]. Intraplate earthquakes have the potential for especially high seismic hazards because they affect regions with relatively little preparation for seismic events, and frequently include urban areas with high population density. [6] The increased danger to these areas requires innovative solutions. Our research is a detailed search for small and medium earthquakes in the conterminous U.S. [7].

Earthquakes recorded by the USGS catalog have two classifications: quakes and non-earthquakes. The second group includes seismological events triggered by unnatural causes, most of them anthropogenic. [8] They have been registered since 1950 in the U.S. Prominent examples include events on the West Coast due to the nuclear projects near Las Vegas, Nevada. These events are now described as caused by nuclear tests in Nevada and Colorado.

Before 2000, mid-continent or intraplate earthquakes were a rare occurrence. With an increased seismological network that records all magnitude events, a much larger range of small tremors has been detected. However, only in 2010 did the enhancement of intraplate shakes on the Oklahoma/Kansas border indicate anthropogenic causes [9] [10] [11] [12].

Our recent [13] paper showed the primary cause of these tremors was wastewater wells, sometimes called class II wells that increased in number along with the Oklahoma/Kansas border. 206,703 wells cover Oklahoma in different locations; however, the highest magnitudes and frequency of shakes center in a place known as Mississippi Lime, which includes northern Oklahoma and Southern Kansas. Earlier records in this area showed only three events $M \geq 4$ from 1965 to 1980. During the last three years as seen later, 2014-2016 earthquakes enhanced in magnitude and frequency. It agrees with the increasing drilling in Mississippi Lime from oil/gas companies.

Oil and gas companies tend to discourage researchers searching for connections between their activities and tremors for several reasons. They propose an augmented number of jobs and claim that the events are too small to endanger the population. The first supposition is false since employment generally only increases during the initial six months. The second statement is also misleading because small quakes become major events that menace people directly and poison the watersheds. Wastewater contaminated by fracking has been used to irrigate agriculture fields in California [8].

In the area described along the Oklahoma-Kansas border, earthquakes $M \geq$ 4.0 happened five times during the period 1950-2000. From 2010 to the present day, there were 80 trem or sabove this magnitude. The new catalog record classifies non-earthquakes as the following: snow, landslides, nuclear tests, and rock bursts. So far, they do not identify the earthquakes at the border between Okla- 
homa and Kansas as having anthropogenic causes.

Earthquakes triggered by anthropogenic causes happen in the conterminous U.S. in different rates and locations. Some regions present small and medium events apparently by fracking; others show no seismic occurrences even though fracking takes place in the area. Initially, these earthquakes seem connected to subsurface tectonic features such as faults, but it currently is not possible to support this assumption since no faults maps that cover the United States [13].

From the wells data, there are problems; some wells were withdrawn, inactive or stopped working, started pumping, or not reported. Companies do not release complete information regarding the type of the well, [12]. Therefore, in this paper, the number of wells in the locations is without specifying the type. The total of wells in the conterminous USA was 1.7 million in 2015. The impossibility to request this kind of data directly from the companies only allow us to guess how much wastewater wells relate to seismological events. The data for gas and oil wells in this study were drawn from EIA and Frac Focus.

Intraplate earthquakes appear to be caused by geological processes such as changes in stress on therock below the surface posed bythe deposition and erosion of surface rock. When this stress on subsurface rock increases or decreases, rock deformation can weaken the stability of surrounding faults. However, this theory fails to fully explain intraplate events since many small earthquakes happen far away from any known fault [3] [8].

Ellsworth [14] agrees that the number of earthquakes related to fracking has increased and industries should monitor them more effectively. As we will discuss later, this increased observation is crucial in parts of Oklahoma. McGarr et al., [15] studied anthropogenic seismicity and described howhuman-caused earthquakes are more apparentis some regions more than others because background seismicity is low.Our research finds that events in the midcontinent are easier to observe about human activitycompared to the California coast, which has a higher rate of interpolating seismic activity.

McGarr, [15] studied the maximum magnitude of earthquakes induced by fluid injection. He proposed a model to predict how large an earthquake induced by fluid injection or other methods could be. His conclusions pointed out that "maximum seismic moments are limited based on the total volume injected in the environs of the induced earthquakes". Earthquakes occurring in spatial and temporal proximity to such operations as hydraulic fracture are immediately under suspicion to be triggered or induced. It is not yet perfect how to discriminate between induced, triggered and natural seismicity, but some researchers are trying to make clear rules and establish scientific methods for this purpose. Those papers presented valuable theoretical ideas on the processes and the influence of unconventional wells or wastewater disposals in the propagation and increase of earthquakes. In spite of this research, however, the central question remained why the wastewater wells affected some areas, and other locations were uneventful.

In 2014, Texas had alarger number of wells compared to Oklahoma, but 
earthquakes $M \geq 4$ absent. Texas had 50,000 disposal wells, servicing around 216,000 active drilling wells, according to Railroad Commission. Each well used about 4.5 million gallons of chemical-laced water, according to [8]. Although there are wells informed overall states, a cluster of quakes happened more in regions near Dallas and at the west end of the state.

There were records in the USGS data catalog belonging to the conterminous U.S. classified as non-earthquakes. [16] In this topic of non-earthquakes, we tried to isolate those clearly connected with human activities. Next, we searched for events categorized as quakes in the mid-continent during the same range of time with magnitude $M \geq 4.5$. The next section researched intraplate earthquakes located near the Oklahoma/Kansas border in the Mississippi Lime region. In this location tremors and wastewater, wells increased since 2010 in either frequency or magnitude. After Oklahoma, we separated more 11 states that use fracking tofollow the quakes evolution during the same period to find out if it would be connected or not with fracking. (Table 1) With the results for those states, plus the observations made for 40 states in the conterminous USA, (Table 2) we found out that fracking is not the only explanation of increasing small seismological events. We applied a theory that can clarify the apparent disparities observed for each location, which is the Griffith approach [17] [18] [19] [20] [21].

\section{Anthropogenic Action in the U.S., 1950-2016}

We divided earthquake studies into time, regions, magnitude. Figure 1 shows tremors $M \geq 3.5$ during the period 1950-2017 registered as non-quakes. The magnitude level corresponds with the USGS threshold of completeness. The majority of events happened in the Western U.S.

Table 1. The tremors average variations in the period 2000-2016, it included 11 states.

\begin{tabular}{cccccccccccc}
\hline States & Arizona & Arkansas & California & Colorado & Idaho & Kansas & Missouri & Nevada & Montana & Oregon & Texas \\
\hline 2000 & 3 & 0 & 0.4 & 2.4 & 0.1 & 0 & 0.1 & 0.1 & 0.2 & 0.1 & 0 \\
2001 & 3 & 0 & 0.4 & 2.5 & 0 & 0 & 0.1 & 0.2 & 0.1 & 0.1 & 0 \\
2002 & 1.5 & 0 & 0.4 & 2 & 0.2 & 0 & 0 & 0.1 & 0.1 & 0.3 & 0.1 \\
2003 & 0 & 0 & 0.4 & 0.4 & 0 & 0 & 0.1 & 0.1 & 0.1 & 0.1 & 0.1 \\
2004 & 0 & 0 & 0.4 & 0.2 & 0.1 & 0 & 0.1 & 0.1 & 0.1 & 0.4 & 0 \\
2005 & 0 & 0.1 & 0.3 & 0.5 & 0.1 & 0 & 0.1 & 0.1 & 0.2 & 0.1 & 0 \\
2006 & 0 & 0 & 0.4 & 1 & 0.1 & 0 & 0.1 & 0.1 & 0.1 & 0.1 & 0.1 \\
2007 & 0.1 & 0 & 0.5 & 0.6 & 0.1 & 0 & 0.1 & 0.1 & 0.1 & 0.5 & 0.1 \\
2008 & 0.1 & 0.2 & 0.6 & 0.6 & 0.1 & 0 & 0.2 & 0.2 & 0.1 & 0.1 & 0.4 \\
2009 & 0.1 & 0.1 & 0.6 & 0.6 & 0.1 & 0 & 0.1 & 0.1 & 0.1 & 0.2 & 0.3 \\
2010 & 0.3 & 2.6 & 2 & 1 & 0.3 & 0 & 0.5 & 0.2 & 1.5 & 0.4 & 7 \\
2011 & 0.1 & 9 & 1 & 1 & 0.1 & 0 & 1 & 0.2 & 0.2 & 0.3 & 2 \\
2012 & 0.3 & 0.2 & 1 & 0.4 & 0.1 & 0 & 0.5 & 0.1 & 0.3 & 0.3 & 1 \\
2013 & 0.2 & 0.4 & 0.7 & 0.7 & 0.2 & 0 & 1 & 0.2 & 0.2 & 0.7 & 1.5 \\
2014 & 2 & 1.6 & 3.5 & 0.8 & 4 & 3 & 3.2 & 5 & 3 & 4.5 & 1 \\
2015 & 1.7 & 1 & 4 & 0.6 & 5 & 4 & 5 & 6 & 4 & 4.4 & 2 \\
2016 & 2 & 0.6 & 4.5 & 0.7 & 4.5 & 9 & 3 & 4 & 5 & 2.8 & 0.3 \\
\hline
\end{tabular}


Table 2. States, wells number (reported 2015), Year of maximum earthquakes, possible causes. There are 40 states displayed. North Carolina has wells but does not release the information. The item named "explosions" are unidentified artificial sources. (USGS, Frac Focus.)

\begin{tabular}{|c|c|c|c|}
\hline States & Wells & Quakes Max. & Possible Causes \\
\hline Alabama & 8017 & 2013 & Frack \\
\hline Arizona & 369 & 2014 & Frack \\
\hline Arkansas & 18647 & 2011 & Frack \\
\hline California & 105037 & 2016 & Frack \\
\hline Colorado & 72313 & 2001 & Frack, Mines, Coal \\
\hline Florida & 123 & 2016 & Explosion \\
\hline \multicolumn{4}{|l|}{ Georgia } \\
\hline Idaho & 152 & 2014 & Frack \\
\hline Illinois & 69222 & 2013 & Frack \\
\hline $\begin{array}{c}\text { Indiana } \\
\text { Iowa }\end{array}$ & 7672 & 2013 & Frack \\
\hline Kansas & 252097 & 2015 & Frack \\
\hline Kentucky & 32483 & 2012 & Frack \\
\hline Louisiana & 64710 & & \\
\hline Maine & & 2016 & Frack, Mines \\
\hline Michigan & 19821 & 2013 & Frack \\
\hline Minnesota & & 2016 & Sand Frack, Mines \\
\hline Mississippi & 7897 & & \\
\hline Missouri & 6590 & 2015 & Frack \\
\hline Montana & 19920 & 2010 & Frack \\
\hline Nebraska & 19821 & & \\
\hline Nevada & 250 & 2015 & Frack, Nuclear, Mines \\
\hline New Mexico & 60943 & 2010 & Frack \\
\hline New York & 24435 & & \\
\hline North Carolina & (?) & 2015 & Mines,Frack(?) \\
\hline North Dakota & 17931 & & \\
\hline Ohio & 1916 & 2013 & Frack \\
\hline Oklahoma & 206373 & 2015 & Frack \\
\hline Oregon & 522 & 2014 & Frack, Mines \\
\hline S. Carolina & & 2015 & Mines \\
\hline Pennsylvania & 136373 & 2013 & Frack \\
\hline Tennessee & 15814 & 2015 & Frack \\
\hline Texas & 291996 & 2010 & Frack \\
\hline Utah & 27352 & 2014 & Frack, Mines \\
\hline Virginia & 11850 & 2013 & Frack \\
\hline Washington & 721 & 2004 & Frack, Explosions \\
\hline $\begin{array}{l}\text { W. Virginia } \\
\text { Wisconsin }\end{array}$ & 109373 & 2013 & Frack, Mines, Coal \\
\hline Wyoming & 66298 & 2010 & Frack, Mines, Explosion \\
\hline
\end{tabular}




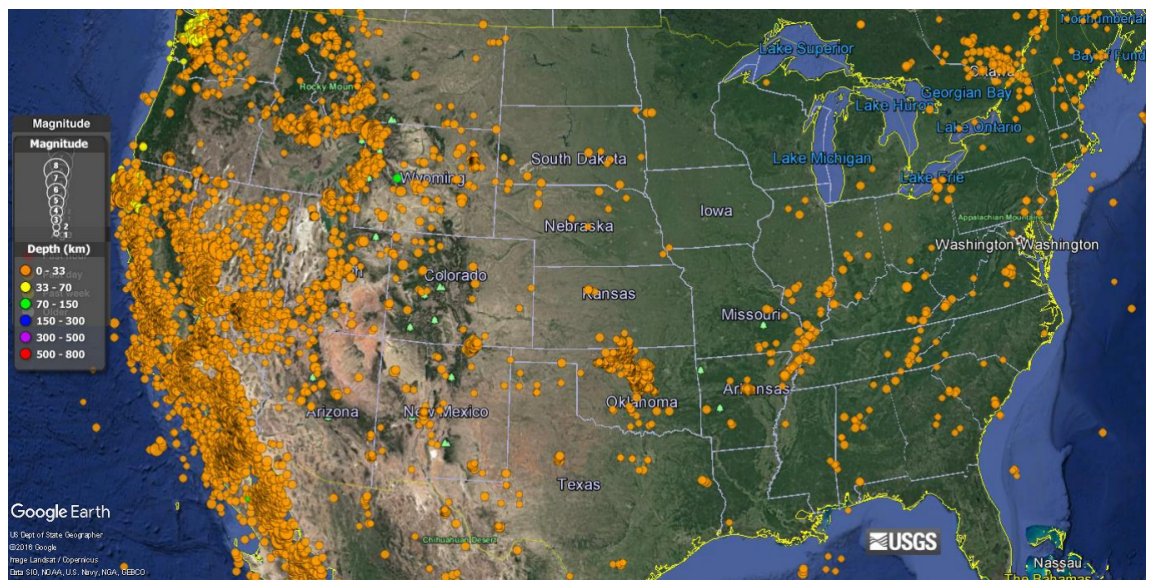

Figure 1. Events considered non-earthquakes M3.5 or above, in the period 1950-2016. Earthquakes recorded mostly in the Western U.S.

The non-earthquakes events are classified by USGS as follows: chemical explosion, experimental explosion, mine collapse, mining explosion, nuclear explosion, quarry blast, and rock burst. The total in the range 1950-2016 was more than 800 events. The states most affected were Washington, Oregon, California, Wyoming, Colorado, Nevada, and Arizona. In Wyoming, the intensification of mining exploration is creating several clusters of tremors. On the east coast, an event classified as an "experimental explosion" in Florida in 2016 was the only non-quake recorded, despite the presence of several wells. The other events on this side of the country were in Virginia and Alabama, both connected to mine collapses. An item of particular interest was an M5.8 tremor in Nevada, far away from any obvious fracture orfault, caused by nuclear tests. It would indicate that it is unnecessary for a particular geological formation to collapse to trigger an earthquake; other sources of tension, stress or pressure, can affect seismic events.

The definition of "induced" is a small tremor created by anthropogenic reasons, but high-intensity tremors can certainly be connected to human influence. Our public records show one in Nevada (1976) with an intensity of M5.8 that was triggered by nuclear tests. [16] The last nuclear test was in 1992, documented as anM5.1 earthquake in the same location northeast of Beatty, Nevada with a depth of $0 \mathrm{~km}$ and contaminating a large area with radioactivity. Over 41 years, the federal government detonated 921 nuclear warheads underground at a Nevada Test site, 75 miles northeast of Las Vegas. Each explosion deposited a toxic load of radiation into the ground, sometimes directly into aquifers. A similar case occurred in Colorado, in 1973, triggering earthquakes M5.4. Those human actions triggered earthquakes, which reached magnitudes well above the ones considered "induced". In addition to the possibly damaging seismic effects, the evident contamination of soil is a significant factor in environmental pollution.

The Central U.S. region presented enhancement of small events supposedly triggered by natural causes. The coordinate boundaries for this search were $48.73 \mathrm{~N}, 32.17 \mathrm{~S},-90.52 \mathrm{E},-107.18 \mathrm{~W}$. To distinguish possible increases, we 
divided into two periods 1950-2009 and 2009-2016. In the first period, only 37 events considered quakes or non-quakes $M \geq 4$ occurred in the target location. Only two events in Oklahoma were M4.5. After 2000, in 16 years the number of earthquakes in this region increased more than three times. Tremors with magnitudes $M \geq 4.5$ also increased most in Oklahoma [9] [10] [11]. Figure 2 highlights the two events $M \geq 4.5$ in the period 1950-2009.

Figure 2 shows enhancement of intraplate events and evidence of medium earthquakes $\mathrm{M}>4.5$ during the years 1950-2009 in the central U.S. Oklahoma displayed the highest intensity incidents in the period with events of intensity M4.5 in 1974 and 1997.

Figure 3 presents the central U.S. during the period 2009-2016. Surprisingly we observe that the number of events on the Western coast decreased, while Oklahoma mainly increased with the significant events 2011-2016. The evidence

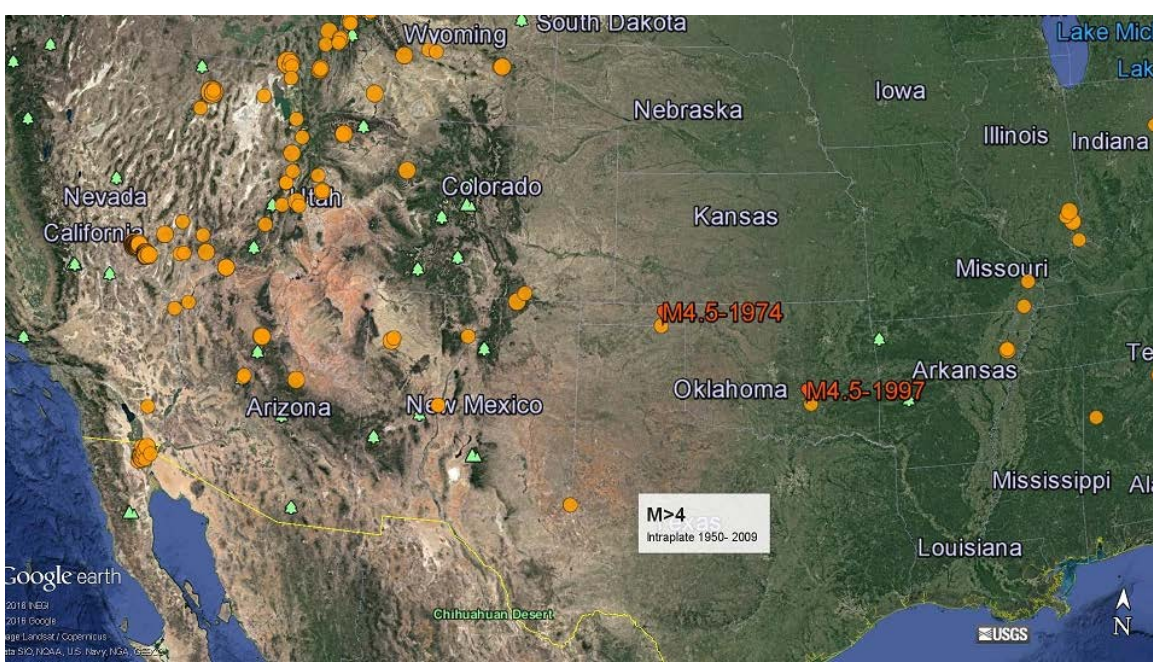

Figure 2. Conterminous U.S. and Midcontinent and earthquakes M 4.5 and above during the period 1950-2009.

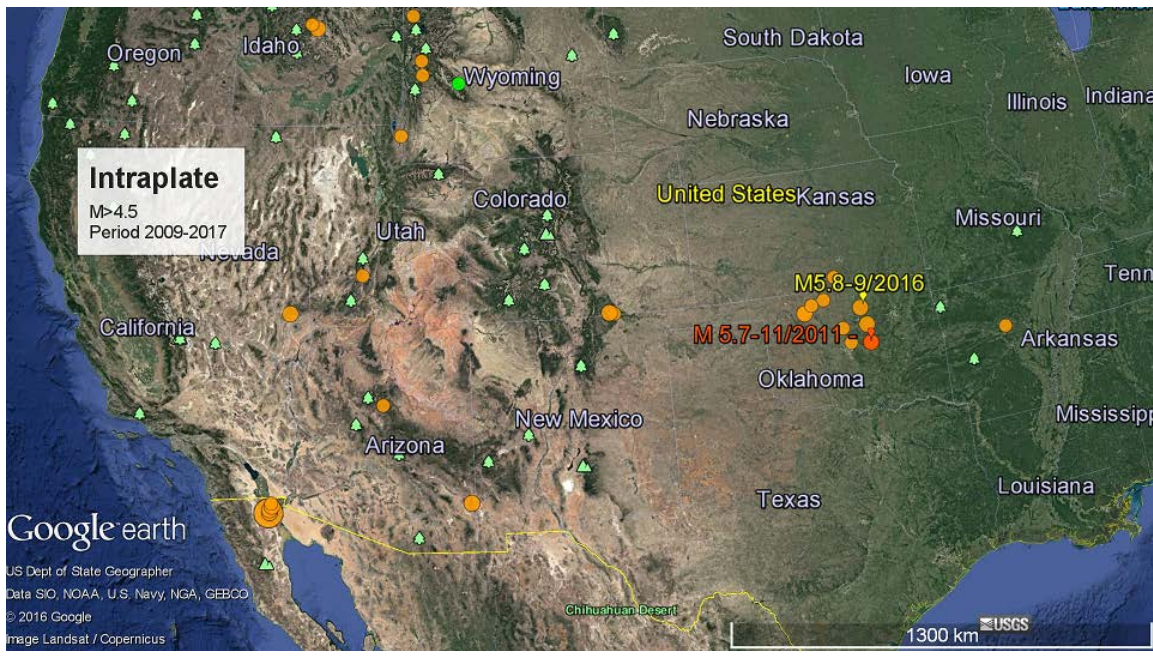

Figure 3. Events occurring in the period 2009-2016 mid-continent, $M \geq 4.5$. Two events $M \geq 5$ in Oklahoma in a region where medium earthquakes were rare until 2009. 
in these three figures denotes an apparently anthropogenic factor discharging sufficient energy beneath the earth's surface to trigger earthquakes. Comparing the three figures, the effects of human actions are clear in the Western states since 1960 when underground nuclear tests in Nevada started. Although the nuclear testing apparently stopped in 1992, the pollution and contamination of the soil are factors that must be considered. Also, the magnitude of the earthquakes reached M5.8 as recorded; these are not a small tremor or shake as induced earthquakes are officially defined. Another issue is the decay or post shot activity increases the seismicity for one or two days following the tests. Artificial or anthropogenic events create clusters of shakes or aftershocks that propagate for hours or days.

Physical and geological reasons partially explain the events as the extensive exploration of the midcontinent bycompanies engaged in coal, gas, oil, and methane exploration (Colorado), as well as chemical explosions, and rock bursts in deep mines. All of these factors contribute to seismic disturbances that happened even when far from known faults, dikes or joints [17].

The next section focuses on Oklahoma with the excessive human interference in the mid-continent environment.

\section{Intraplate Earthquakes in Oklahoma (One State Study)}

The study of intraplate earthquakes in Oklahoma in our past report [12] suggested that fracking triggers seismic events. However, we did not have sufficient data to show how these variations were dramatically different from earlier periods. This study in Oklahoma is starting to focus on the increase of $M \geq 4$ earthquakes. To make a stronger analysis, we studied the period 2000-2016 across all the conterminous U.S. and Oklahoma for events $M \geq 4.0$. The first results appear in Figure 4 and Figure 5. Figure 4 displays the evolution of earthquakes in the period 2000-2016 in the conterminous U.S., compared with the mid-continent alone. Figure 4 shows the enhancement of earthquakes in all categories of magnitude after 2010, which correlates with more wastewater wells in the area known as Mississippi Lime. The results showed the progressive enhancement of events in the region over the last three years.

For events $M \geq 3.1$, a sudden growth occurred in 2011, and $M \geq 4$ began to rise starting in 2013. The conterminous U.S. shows an enhancement of events in 2010, mostly on the California coast [1] [2] [3] [4] [5]. The mid-continent presentsa progressive increase of events since 2014 with an apex in 2015 as Figure 5 indicates.

The Figure 5 show that earthquakes near the border between Oklahoma and Kansas are higher than in any other location mid-continent. The year of maximum activity for mid-continent events was in 2015, and occurrences are still growing. The year of maximum activity for the conterminous U.S. was 2010, and that count is now decreasing. The possible explanation for the Oklahoma peak in events is that the wastewater wells in the Mississippi Lime region are awakening mature fractures of faults in the area that have previously unknown to scientists 


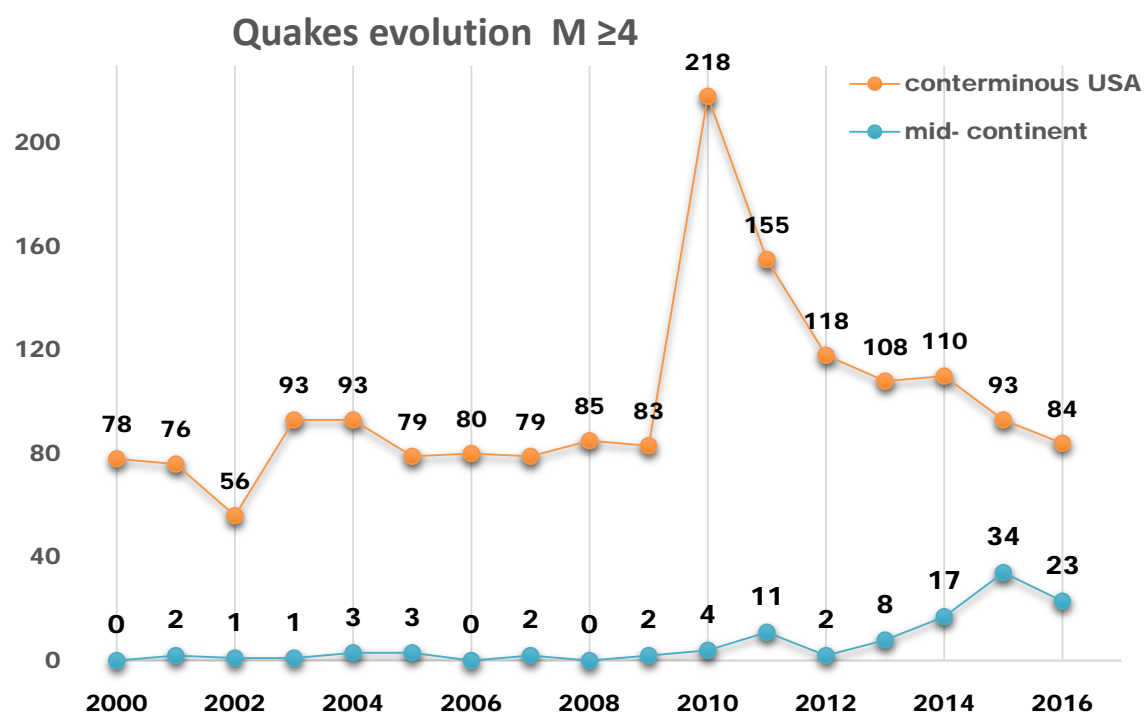

Figure 4. The quakes events $M \geq 4$ in the conterminous U.S. and Oklahoma showing different years for maximum frequency. The Conterminous U.S. had a maximum in 2010 and mid-continent in 2015, most along the Oklahoma border with Kansas.

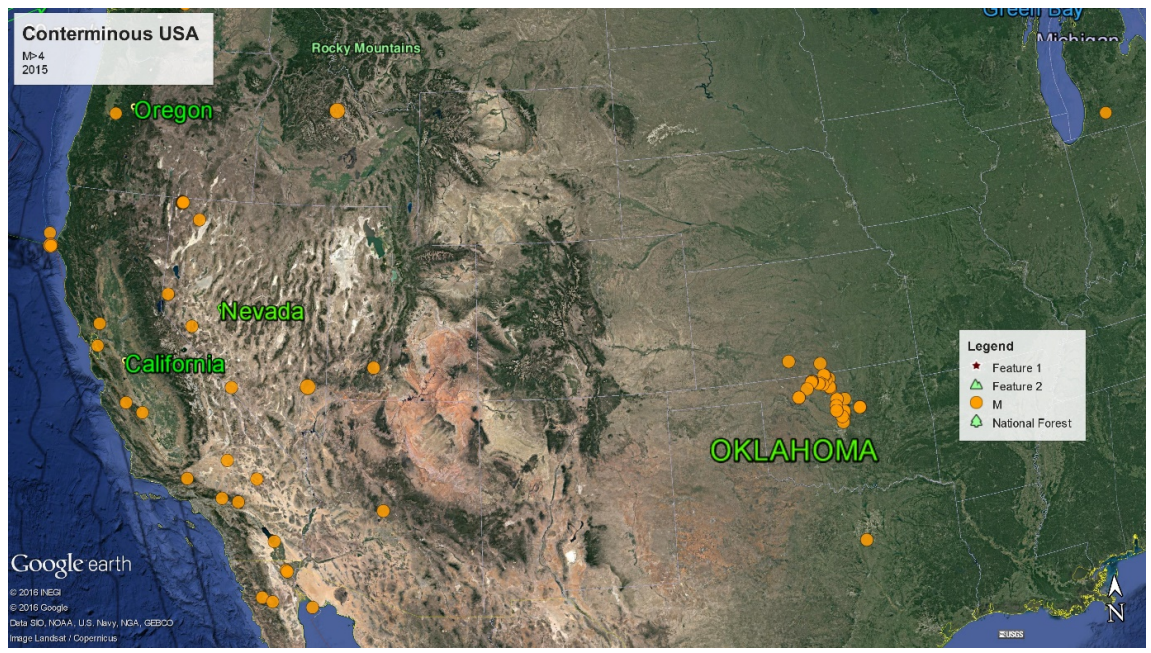

Figure 5. The Conterminous U.S. during 2015 the maximum of earthquakes $M>4$ (observe the intraplate in $\mathrm{Ok})$.

and researchers. A search for underground faults remains incomplete, especially in the mid-continent. No maps are available showing small fractures or faults in the Great Plains, especially in the mid-continent where several layers have been deposited over each other, and the tectonic structure in those regions changed several times. The mid-continent thickness is about $45 \mathrm{~km}$ in some locations. The first results in Figure 4 and Figure 5 indicated an increasing stress in the area known as Mississippi Lime. After 2011, there is a slow enhancement of quakes magnitude $M \geq 4$, which peaks in 2015. A glance at the variation of tremors for depth shows that over the last three years, events at depths $1-60 \mathrm{~km}$ increased in the Mississippi Lime region. This growth happened in the $1-10 \mathrm{~km}$ range, rising to a peak in 2015. Looking for deeper depths or below $20 \mathrm{~km}$, we 
found records of tremors only after 2014.

Two causes trigger earthquakes in the region:

The successive strain, pressure, and tension that enhance crack growths due to oil/gas wastewater wells, and other new techniques.

Fractures buried in the shallow depths but recently reactivated, which researchers have ignored so far.

\subsection{Method to Construct Oklahoma Plots}

Next, we search for records during the period 2000-2016 only in the Mississippi Lime. Our procedure divided events according to magnitudes in the following ranges: M0 - M2, M2.1 - M3.0, M3.1 - M4 and, M $\geq 4.1$ during the specified time.

Our plots are constructed as follow in this example;

Total number of events magnitude category M3.1 - 4.0 = 1832 events

Total number of events $/ 16$ (number of years) $=$ average $=114$ events $/$ year

The average number is compared with each year events, period 2000-2016. The results found pointed out that only after 2010, all the categories started to enhance. The year 2010 is just one year after the new fracking technicsbegan in Oklahoma.

Since 2010, most categories exceed the average established. The last three years shown in Figure 6 demonstrate increasing tremors at magnitudes $M \geq 4$. Tremors decreased during the last year (2016), coinciding with the shutdown of some wells in the region. In section 3, we show that the fatigue of the material and the processes involved in drilling especially in determined locations is enough to trigger and enhance small and medium earthquakes.

If there is a present fracture, it will increase the probability that will happen sooner. Mississippi Lime [10] is one of the regions most exploited in the central area of the USA. This region is also one of the many that belong to the conglomerate the shales around the country. This region is part of an ancient ocean covered by the Great Plains. It createdan uplift in the Kansas/Oklahoma border where several faults and fractures can be in layers, which under stress might trigger earthquakes. The magnitude of an earthquake is determined by the amount of pressure, tension and strain the region suffers over a short or longer time span. The longer the force is exerted increases the chance that the tension in unknown buried fractures will unsettle and trigger earthquakes of greater magnitude.

Since 1990, Oklahoma has extracted oil and gas with fracking without connection to earthquakes. Since 2009, the extraction in the area known as Mississippi Lime has reached exceptional values in a small region.

In Oklahoma over the past three years, earthquakes have escalated in a frightening way without explanation. The review on hydraulic fracking showed that many probes could reach $1-4 \mathrm{~km}$ deep in Oklahoma. Corresponding to the depth of the majority of small tremors, which were enhanced by $100 \%$ in the same depths. 


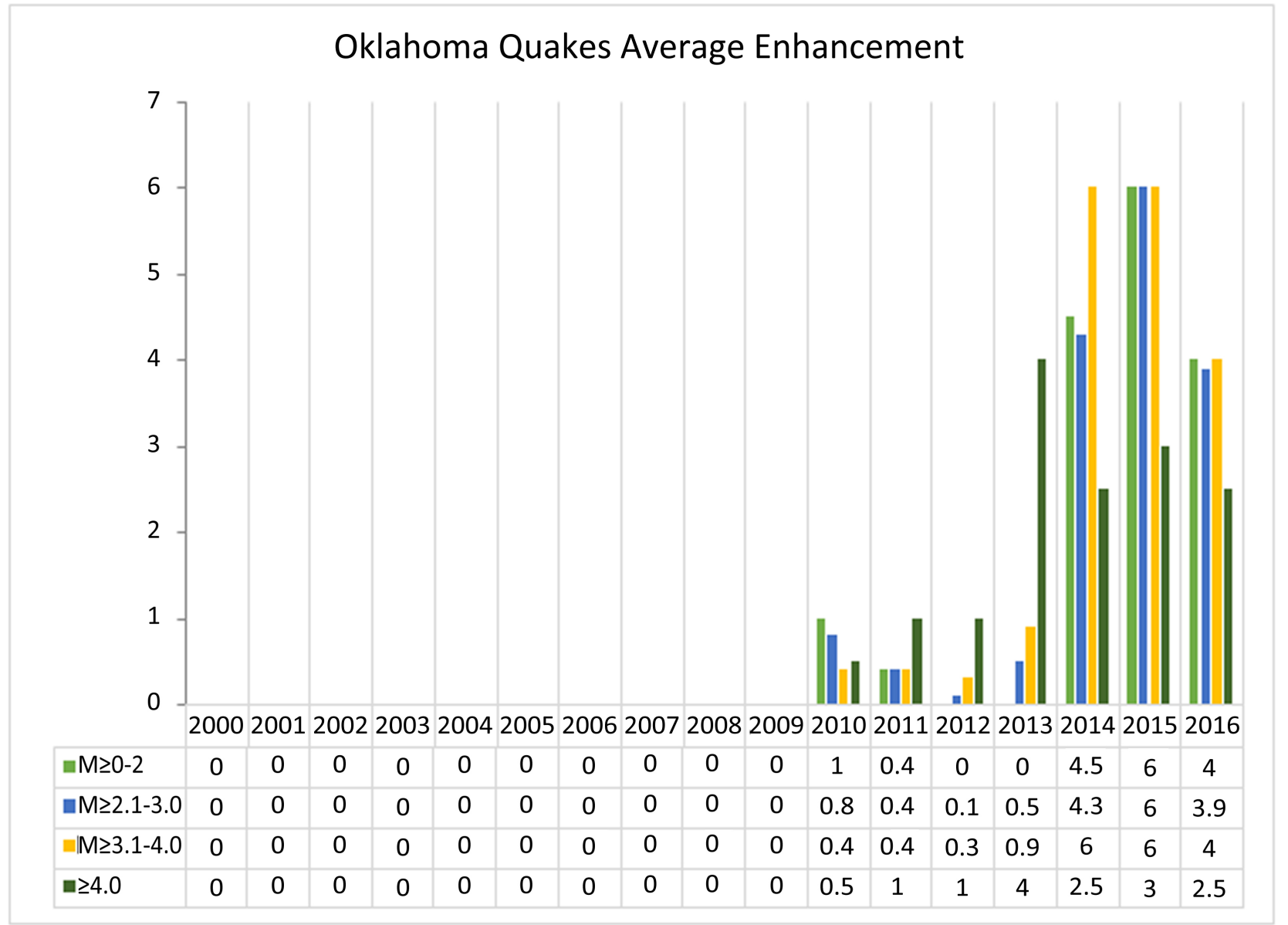

Figure 6. The variation of quakes for each magnitude analyzed as described in the paper, the highest numbers are for the last three years when the percentage of events would exceed the average amount.

Most earthquakes in the region, small or medium, are also at the same depth. There is an indication from fracture mechanics that the stability of the crack is jeopardized by the new drilling technics. Eventually, some of these fractures were reactivated by resource exploration.

We showed that the average of small events in the period 2000-2016 displayed a tendency to occur in the same locations.

\subsection{Areas Triggering Anthropogenic Events in the U.S.}

The Table 1 shows the variation of eleven states in the period 2000-2015. Some states increased the instances of tremors and quakes over the last three years. Table 1 lists the events in the states Arizona, Arkansas, California, Colorado, Idaho, Kansas, Missouri, Montana, Nevada, Oregon, and Texas. The numbers do not represent the real number of events they are the average of each year during 16 years in all the 11 states examined. Since in this case, we have an entire range of magnitudes the considered them in the Table and the next plots. It means for example in the first state Arizona, had an increase of events in 2000, 3 times the average, in the interval 2003-2013 was zero or below one. It only enhanced last three years. 


\subsubsection{Method Applied to Construct the Table 1 and plots}

A similar method from Oklahoma plot was used to build the strategies to states in an increasing number of shakes. For each state we did:

Total number of events with small and medium magnitude during 16 years in each of the ten states with more events $=$ Total

Total/16 (number de years analyzed) $=$ average

Average compared to each year in the range 2000-2016.

It indicated that a state as Kansas had any tremor above the medium until 2014, as you see in Table 1 or in the plots Figure 7 and Figure 8. We divided into two different plots because some had more tremors as California, we would not distinguish the differences, easily.

The next two figures are seismological average variations in the eleven states that use fracking. In the illustration (Figure 7), earthquakes increased 20142015 in California, Idaho, Kansas, Nevada, Montana, and Texas. Texas had a decrease in the shakes in 2016but showed a strong enhancement in 2010,especially in Central and Western Texas. In Figure 8, a dramatic enhancement of shakes occurred in Arkansas in 2010 and 2011 and decreased2014-2016. Arizona, Colorado, Missouri and Oregon presented event surges in 2014-2016. Two of these states, Arkansas and Colorado, amplified shakes in 2000-2002, but the causes for these variations were diverse.

Kansas, a state without a history of major earthquakes, increased the number of events more than California and any otherstate. The observations indicated

\section{Average seismological variations}

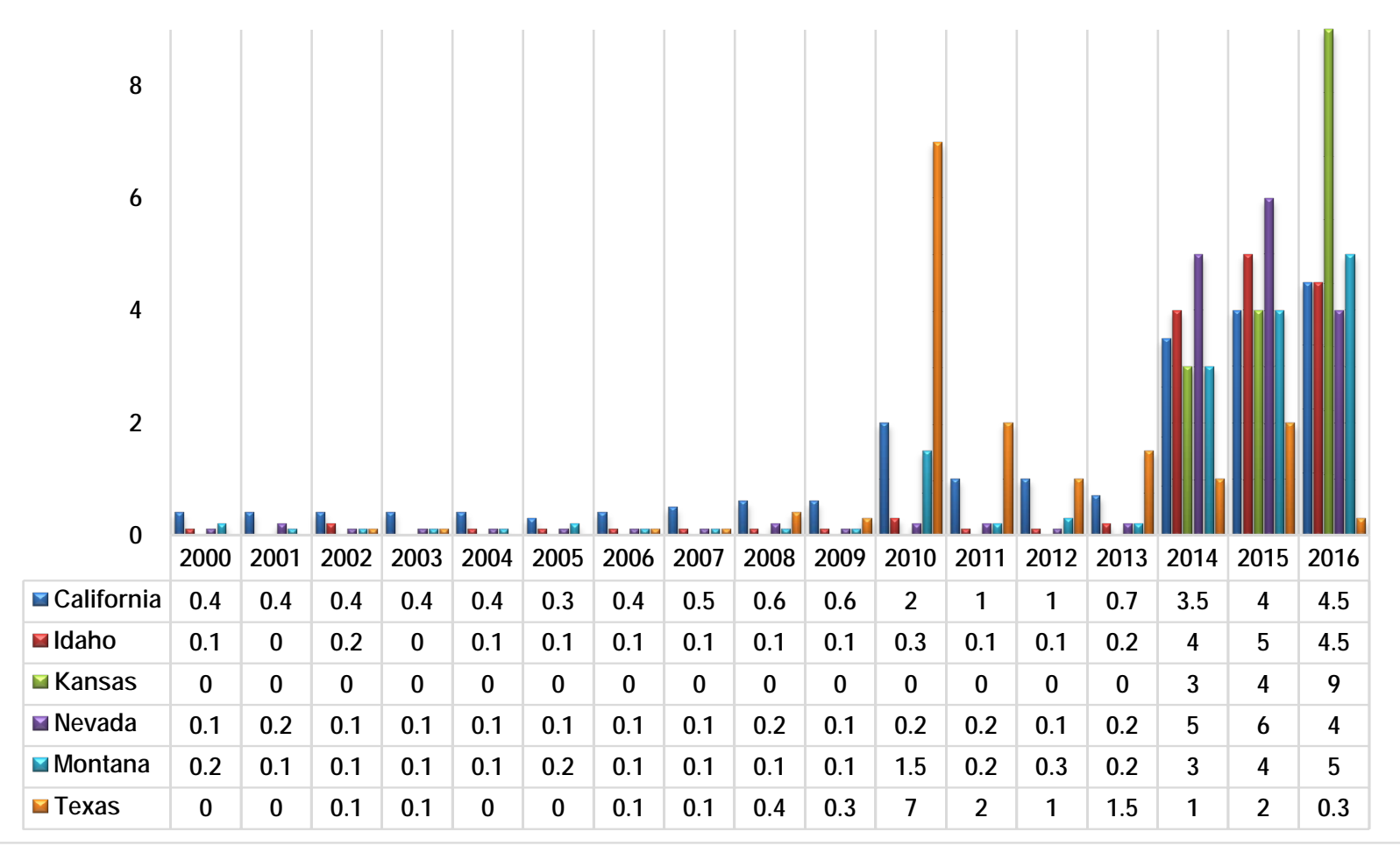

Figure 7. California, Idaho, Kansas, Nevada, Montana, Texas enhancements and evolution of earthquakes last sixteen years. 


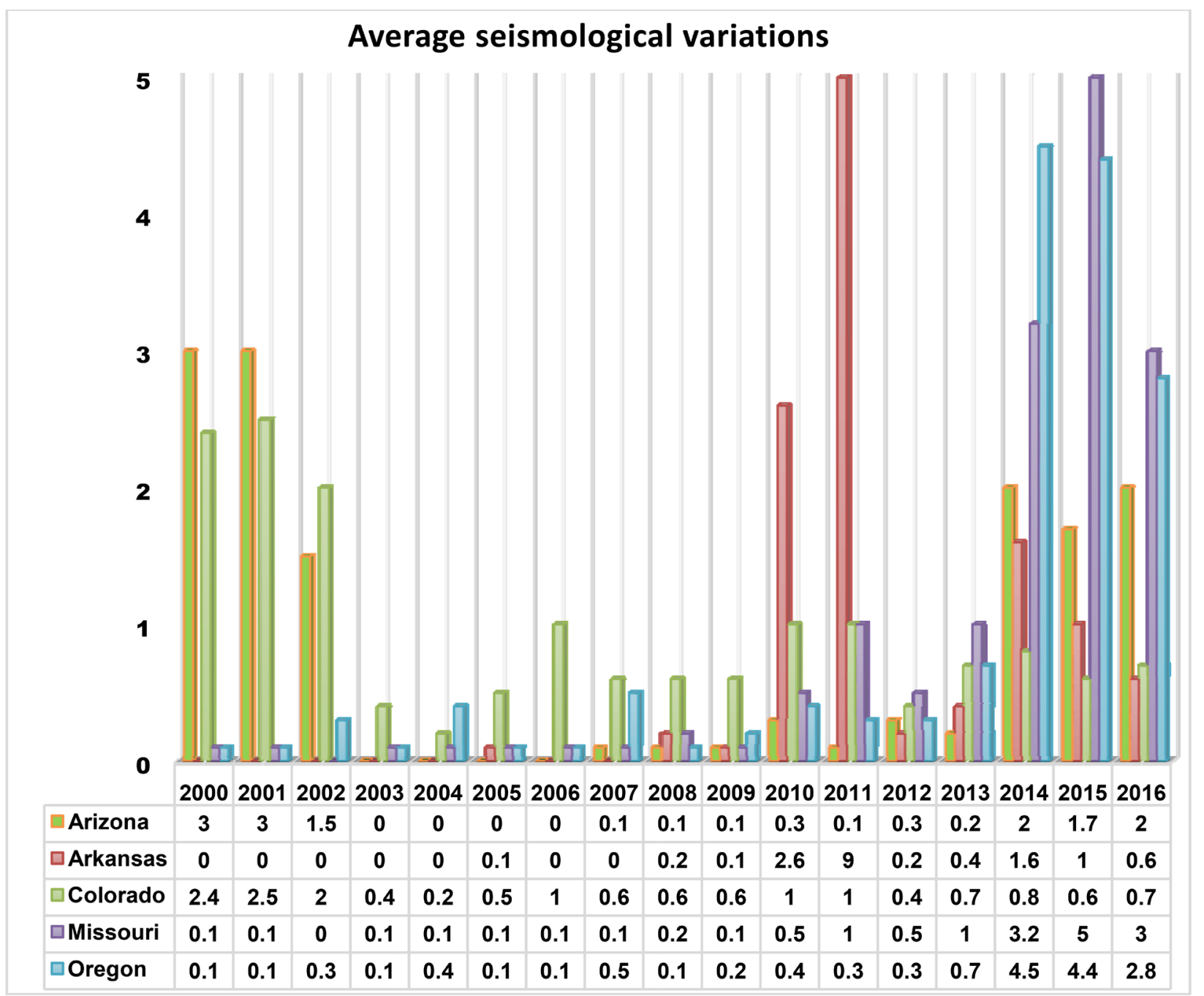

Figure 8. Five other states are enhancing earthquakes period 2000-2016. The 2014 and 2015 showing intense activity for Arizona, Arkansas, Colorado, Missouri, Oregon and a decrease in 2016. New politics for those areas can explain the difference observed.

that other regions rise higher than California eventsin some years. California is a location where small and medium earthquakes had thehighest occurrences. Frac Tracker researcher Matt Kelso [11] explains thatTexas has more than 300,000 active oil and gas wells. Texas is the only state charging a fee for researchers to obtain location data for its wells and Frac Tracker chose not to publish the raw data or depict it on the map becausethe state does not allow the data redistributed. For example, Frac Tracker data shows that in Colorado, energy companies are feverishly drilling and fracking the Niobrara shale and other formations in the Denver-Julesburg Basin for crude oil and natural gas. This region ranks fourth in the nation for total active well count-84,357 active wells.

The next six states showed moderate variations over the past three years, but increases in other years as Arkansas did in 2010, 2011. The greatest discrepancies occurred in California 2009, Texas 2010, and in Arkansas 2010 and 2011. This region is also one of the many that belong to the conglomerate the shales around the country. These discrepancies require further investigation. Nevertheless, the 
fluctuations observed in the first six states (California, Idaho, Kansas, Nevada, Montana andTexas) are less than in the next five states: Arizona, Arkansas, Colorado, Missouri, and Oregon.

\subsubsection{Triggering Earthquakes Mid-Continent}

The last part of this paper works to demonstrate the relationship between human actions and earthquakes. We constructed a Table 2 with the conterminous USA, some of the states showing quake enhancement, well counts, and possible causes for those improvements. The Table 2, working the same period 2000-2016 for 40 states also displaying the number of active wells (2015), the states without wells, the enhancement of quakes for each of state, and the year it occurred. The last column is the possible cause of those enhancements each state behaving differently. As an example,Florida has 123 documented wells and no earthquakes but in 2016 was some earthquakes offshore triggered by the experimental explosion. Another one, Maine, has no wells but an increase of tremors explained by the first attempts to frack in the area since 2013 and in other years by the mines.

In Table 2, seven locations did not have wells, but four of them still have small events as Maine, Minnesota, S. Carolina and N. Carolina.

The second column is for the Year of maximum tremors; some states did not show any shakes, including Georgia, Iowa, Louisiana, Mississippi, Nebraska, New York, North Dakota and Wisconsin. There are 32 locations with wells, from them 28 doing fracking, have wastewater wells and have tremors. However, 4 of those states although have wells do not have earthquakes. The Table identifying the states, with wells or not, and the possible causes of tremors. Nine locations showed multiple sources triggering quakes. Lastly, some areas do not have wells and still present an increase in tremors in the year identified in the Table. Below follows, the explanation of results presented in the Table for each state studied.

Colorado and Wyoming show unexplained explosions as part of the seismological disturbances in the area. Wyoming is an area of risk being near Yellowstone Park with a high number of seismological disturbances recorded in recent years. Apparently, there are now, 66,298 wells and several projections to increase that number. The growth of events in this area appears to connect the wells and the deep mining. Colorado also presented events clusters in regions with gas exploration and coal methane. California today has more than 10,000 small events every year; at the beginning of 2000, the state presented 1500 small events. From the few states with no wells, most had no quakes, such as Georgia, Iowa, and Wisconsin. Regions with many wells and little to no activity are Louisiana, Mississippi, Nebraska, New York, and North Dakota. Let us focus on two areas that have not had earthquakes for many years, Maine and Minnesota. The Maine records did not show small earthquakes at first. They started in 2012 with the investigations for hydraulic fracturing enhancing in 2016 on the border with Canada. Minnesota does not have to frack for gas and oil; the fracking is for sand that is also triggering small quakes in the area. There is also a significant result for states with a high number of wells but with few or no quakes: Louisiana, 
Mississippi, Nebraska, New York and, North Dakota.

Texashas 291,996 wells, and few tremors, which appear in swarms near Dallas. Oklahoma has 206,373 active wells, most of them concentrated in the Mississippi Lime area. In this region, many of the higher magnitude quakes happened. At times in recent years, the number of events in Oklahoma has surpassed those in California. The results found in Table 2 indicate that small, sometimes medium magnitude events are a just seismological disturbance by anthropogenic actions. Two states did not have wells and no earthquakes. Some had no wells or fracking, but they involve several other experiments or explorations triggering events in first or minor degree.

The next step was to show a map with all states and the shale basins distribution, current plays, prospective plays, youngest, intermediate, and oldest stacked plays. It is also showing the years when was observed most earthquakes. The ones that had no earthquakes but wells, it is drawn the number of wells in the locations.

The results found in this section are concerning since some places had increased the fracking and wastewater wells and do not present any seismological event or very few. It indicates a possible mechanical structure is happening in the crust able to explain the discrepancies observed in those results. The answer is beyond tension and stress in some area that will trigger an earthquake. It is something that evolves in a period in some regions, and it is not happening in other locations. The next section will explain how it is going on.

\section{Fracture Mechanics and Fracture Toughness.}

Cracks can form due to fatigue of the material or processes involved in the drilling in the determined locale, as in fracking or wastewater wells. A shake happens to depend on which kind of fracture existing in the target area. The theory for cracks in fracture mechanics was developed by Griffith for materials.

There are three ways of applying a force enabling a crack to spread: 1) anopening mode, which is a tensile stress normal to the plane of the crack; 2) a sliding mode, which is a shear stress acting parallel to the plane of the crack and 3) perpendicular to the crack front; and a tearing mode comprised of a shear stress parallel to the plane of the crack and parallel to the crack front, [17]. To study those phenomena [18] [19] [20] [21].

Griffith's criterion is,

$\sigma_{f} \rightarrow$ stress at the fracture

$$
\sigma_{f}=\sqrt{a \approx} C
$$

$\mathrm{a} \rightarrow$ crack length

A crack growth requires the creation of two new surfaces and hence an increase in the surface energy. Equation [2] is,

$$
C=\sqrt{\frac{2 E \gamma}{\pi}}
$$

E-Young modulus

$\gamma$-Surface energy 
Griffith's theory provides an agreement for brittle materials. Irwin has corrected this equation as follow:

$$
\sigma_{f} \sqrt{a}=\sqrt{\frac{E G}{\pi}}
$$

All terms, defined above. On our calculations, the crack will grow for the first mode or opening mode as following;

$$
\begin{aligned}
& G=G_{I} \equiv \rightarrow \frac{K_{I}^{2}}{E} \text { plane stress } \\
& \frac{\left(1-v^{2}\right) K_{I}^{2}}{E} \text { plane strain }
\end{aligned}
$$

$\mathrm{K}_{\mathrm{I}}$ is the stress intensity factor in modes

$v$ is the Poisson ratio the transverse strain to axial strain

$\mathrm{G}$ strain energy release rate.

The $\mathrm{G}$ is higher for higher loads and broader cracks. If the strain energy so released exceeds a critical value $G_{c}$, then the crack growing spontaneously. For brittle materials, $G_{c}$ is equated to the surface energy of the two new crack surfaces. In brittle materials, a crack will growspontaneously if the strain energy released is equal to or more than the energy required to maintain the crack surfaces. The stability condition is

$$
\text { Elastic released }=\text { surface energy created }
$$

We interpret this equation as meaning that the elastic energy released is less than the critical value $G_{c}$, the crack does not grow; equally, it signifies neutral stability, and if the strain energy release rate exceeds the critical value, the crackstartsincreasing in an unstable manner. This process also depends on the material; if the material is ductile,the energy to propagate the crack may increase by several orders of magnitude, as the work to cause plastic deformation is larger than the surface energy. The criterion is restated as:

$$
\text { Energy released }=\text { surface energy }+ \text { plastic deformation energy }
$$

The elastic energy released equals surface energy + plastic deformation energy, which will represent a higher value than the critical value of $\mathrm{G}_{\mathrm{C}}$.

\section{Griffith Approach and Induced Earthquakes}

Let us apply this theory for fracking in vertical or horizontal wells, which may stimulate, reactivate or create new fractures. A vertical well reaches $2.0 \mathrm{~km}$, and horizontal wells reach $2.0 \mathrm{~km}$ vertical depth and an additional $2.0 \mathrm{~km}$ horizontally. In the last case, there are usually several horizontal wells in the same region. By the Griffith/Irwin theory, these fractures in brittle materials could become broader, and above a critical value, $G_{c}$ propagates and triggers small and medium earthquakes. The oil gas companies in the Mississippi Lime area, in particular, have exploited old and new tectonics for over 60 years. Therefore, the increase of cracks in the region would allow crack growth underneath the surface. The relevant variables in these calculations are the Young modulus and the Poisson ratio directly connected with triggering earthquakes. How brittle the 
material in a region increases the possibilities to trigger a tremor. A crack growth is expressed by the Irwin connection as in the equation [3]. If the strain energy released exceeds a critical value $G_{c}$ the crack, or fracture, will grow spontaneously and trigger a quake. The stability conditions are dependent on the equations [6] [7]. Unfortunately, these equations are not time dependent, but the extrapolation may be easier considering a long time that more invasive techniques have been applied in the same locations. It also explains the cracks' evolution in clusters or swarms around the same locality. The same explanation fits with regions that have no events or a lesser number of events compared to the number of wells displayed by the Table 2 . Areas with fewer events are less brittle than others with ahigher number of events.

The same theory enlightens, for example, other anthropogenic events such as mines, nuclear tests, and other bursts displayed in Table 2. In the forty-seven states observed and calculated, most of them presented small earthquakes that agree with the theory for cracks described above. However, a few of them did not show events even though many wells were recorded in the area;this suggests that the rocks and the stratigraphy underground have material that is less brittle and weak, and that does not easily allow a crack to grow. Finally, the fracture toughness is a quantitative way of expressing a material resistance to brittle fracture when a crack is present. A related concept is a work of fracture $\left(\gamma_{\text {wof }}\right)$ directly

proportional to $\frac{K_{I C}^{2}}{E}$, where $\mathrm{E}$ is the Young's modulus of the material and strain. [21] The application of those concepts to earthquakes needs small modifications but, they are able to explain earthquakes swarms when a local area experiences sequences of many shakes striking in a relatively short period. The possibilities of this theory are beyond earthquakes, landslides that happen after the earthquake events also will be explained by the Griffith theory since the material resistance collapse the crack occur and the probability of landslides growing. This landslide assumption needs more elaboration on the equations above, is not discussed on this paper.

\section{Fracking Discussion}

The mid-continent presents a pattern from 1950 through 2009 with few recorded seismic events. After this year, the location called Mississippi Lime on the Kansas-Oklahoma border presents a continuous enhancement of earthquakes in frequency and magnitude until the maximum of occurrences in 2015. Most of those events occurred at shallow depths $1-4 \mathrm{~km}$, the same depth reached by hydraulic fracking probes. Since 2014 the depth of the events increased, at least around Perry, where was a recorded event at a depth of $56.5 \mathrm{~km}$. In modern explorations, fracking probes sometimes reach depths greater than four kilometers. Horizontal wells started to drill around1980, which normally creates multiple horizontal wells in one location.

A single horizontal well allows the drill to reach $2.5 \mathrm{~km}$ in at least four directions and $2 \mathrm{~km}$ deep. Most earthquakes and are probes located at the same 
depth, indicating the area beneath the surface may have had fractures or reactivated fractures that triggered tremors.

The Mississippi Lime region in Oklahoma is located at the edges of the Great Plains, and these occurrences demand more studies to understand the geology and tectonics in the area. Oklahoma is not the only state using fracking; other regions need to be analyzed as well, among them Texas, with the largest number of wells in the country. This study also analyzes an additional40 states with tremors in the U.S. The results pointed out different outcomes as some states had a significant number of wells and no earthquakes, while other regions had earthquakes without wells. The period 2000-2016 showed an enhancement of earthquakes in the middle country, which appears to be consistently linked to fracking. This period also involves the wastewater wells, which reach deeper than the conventional wells in the horizontal or vertical drilling.

A question: what is the maximum magnitude that an earthquake reaches if produced by an anthropogenic action? The answer depends on several aspects of the cracks growth for each location;it is possible for companies to reactivate or create fractures that allow the cracks to enlarge or even collapse. Old fractures may locate at any depth and will remain unknown to geologists until they are reactivated. Despite many years of mineral and energy exploration inthe Mississippi Lime, earthquakes remain relatively small in magnitude in the majority. A major event occurred only after many years of fracturing in the same region.

The evidence of anthropogenic disturbances is clear in Oklahoma, the only state in the Great Plains formation where the magnitude of the events reached the highest rank in the last three years. Reservoirs excessively exploited with primary and secondary recovery will tend to collapse, triggering earthquakes or growing more cracks that lead to new events.

\section{Conclusion}

It is easy to understand the small earthquakes triggered by horizontal drilling or wastewater wells, using the Griffith parameter, it says that fractures in brittle materials will becoming larger, above a critical value Gc propagating in the location around boreholes. Our new experimental results about the earthquakes caused by anthropogenic actions lead us to the Griffith theory for cracks. Through the observations in the entire USA, we noticed that not all the states have seismological responses as predicted for other authors working with fracking. A lot of speculation has been done about the strain and stress that wastewater wells are doing the drilling. However, the real reason triggering small earthquakes is explained by Griffith approach. Indeed, the probability to generate an earthquake after a longer while is greater than other theories for this topic. At this point, there is a lack of information about the buried fractures or faults around the country. The research would be more valuable with the knowledge of them by state or on the country. We observed that Nevada State has a structure where the tremors are smaller than in other regions even though it was nuclear experiments and other heavy exploration there. This report established that in 
many scenarios an apparent "natural" event is produced by anthropogenic causes. Although nowadays fracking and waste water wells are the first causes for the enhancement of earthquakes with small and medium magnitudes, other anthropogenic actions also triggering small earthquakes mid-continent.

\section{Acknowledgements}

Thanks to Paul Killinger editing and correcting the English on this paper.

\section{References}

[1] USGS.

http://earthquake.usgs.gov/earthquakes/recenteqsww/Quakes/quakes_all.php

[2] IRIS. http://ds.iris.edu/wilber3/find_event

[3] IRIS. http://www.iris.edu/hq/ http://www.geomore.com/porosity-and-permeability-2/

[4] Http://www.virginiaplaces.org/geology/naturalgasresources.html

[5] USGS (2011) Assessment of Undiscovered Oil and Gas Resources of the East Coast Mesozoic Basins of the Piedmont, Blue Ridge Thrust Belt, Atlantic Coastal Plain, and New England Provinces, 2011.

[6] http://www.hydraulicfracturing.com/

[7] Indiana Geological Survey.

[8] Kentucky Geological Survey.

[9] Ohio Geological Survey.

[10] Oklahoma Geological Survey.

[11] Kansas Geological Survey.

[12] FracFocus Data-Fracking by Number: Key Impacts of Dirty Drilling at the Stated and National Level, 2014.

[13] Hagen, M. (2015) Mechanism of Intraplate Earthquakes and Anthropogenic Causes in USA. Natural Science, 7, 459-474.

[14] Ellsworth, W.L. (2013) Injection-Induced Earthquakes. Science, 341, Article ID: 1225942. https://doi.org/10.1126/science.1225942

[15] McGarr, A. (2014) Maximum Magnitude Earthquakes Induced by Fluid Injection. Journal of Geophysical Research: Solid Earth, 119, 1008-1019. https://doi.org/10.1002/2013JB010597

[16] Sandvol, E., Seber, D., Sandvol, C., Brindisi, C. and Barazangi, M. (2001) Regional GIS Databases in Support of CTBT Monitoring. 23th Seismic Research Review, Worldwide Monitoring of Nuclear Explosions, 2-5 October 2001.

[17] Griffith, A. (1921) The Phenomena of Rupture and Flow in Solids. Philosophical Transactions of the Royal Society of London. Series A, Containing Papers of a Mathematical or Physical Character, 221, 163-198.

[18] Erdogan, E. (2000) Fracture Mechanics. International Journal of Solids and Structures, 37, 171-183. https://doi.org/10.1016/S0020-7683(99)00086-4

[19] Irwin, G. (1957) Analysis of Stresses and Strains near the End of a Crack Traversing a Plate. Journal of Applied Mechanics, 24, 361-364.

[20] Barenblat, G.I. (1962) The Mathematical Theory of Equilibrium Cracks in Brittle Fracture. Advances in Applied Mechanics, 7, 55-129.

[21] Lawn, B. (1979) Fracture of Brittle Solids. Cambridge University Press, Cambridge. 
Submit or recommend next manuscript to SCIRP and we will provide best service for you:

Accepting pre-submission inquiries through Email, Facebook, LinkedIn, Twitter, etc. A wide selection of journals (inclusive of 9 subjects, more than 200 journals)

Providing 24-hour high-quality service

User-friendly online submission system

Fair and swift peer-review system

Efficient typesetting and proofreading procedure

Display of the result of downloads and visits, as well as the number of cited articles Maximum dissemination of your research work

Submit your manuscript at: http://papersubmission.scirp.org/

Or contact gep@scirp.org 